\title{
Pedagogia da Alternância e Análise Crítica do Discurso
}

p. $82-93$

Jaciele Hosda ${ }^{1}$

Gustavo Biasoli Alves ${ }^{1}$

\section{Resumo}

A Pedagogia da Alternância (PA) é uma proposta de ensino a partir do cotidiano do aluno e tem se destacado em diferentes contextos e práticas institucionais. Assim, também, a Análise Crítica do Discurso (ACD), que leva em consideração o contexto do sujeito, vem ganhando espaço em pesquisas sobre discurso e mudanças sociais. Dessa forma, propomos, neste artigo, comparar a PA apresentado por GIMONET (2007) e FREIRE (1981,1987), e a ADC, de FAIRCLOUGH $(1997,2001)$ e VANDIJK (2008). A partir de uma metodologia de estudo documental e histórico apresentaremos as teorias da PA e da ACD fazendo um comparativo, principalmente, no que se refere ao contexto social, foco de ambas as teorias.

Palavras-chave: Pedagogia da Alternância. Análise Crítica do Discurso.

\begin{abstract}
The Pedagogy of Alternation (PA) is a teaching proposal based on the student's daily life and has been highlighted in different contexts and institutional practices. Thus, the Critical Discourse Analysis (ACD), which takes into account the context of the subject, has been gaining ground in research on discourse and social changes. In this paper, we propose to compare the AP presented by GIMONET (2007) and FREIRE $(1981,1987)$, and ADC, by FAIRCLOUGH $(1997,2001)$ and VANDIJK (2008). From a methodology of documentary and historical study, we will present the theories of PA and ACD, comparing, mainly, to the social context, focus of both theories.
\end{abstract}

Keywords: Pedagogy of Alternation. Critical Discourse Analysis.

\section{Introdução}

A Pedagogia da Alternância (doravante PA) é um método de ensino diferenciado que busca atender o contexto do aluno, fazendo com que ensino e realidade possam trabalhar juntos, unindo em reciprocidade a teoria e a prática. A PA surgiu a partir da necessidade social de um determinado grupo, que a partir de lutas e discussões conseguiu tornar algo possível, acessível e viável.

Para tal comparação e análise será utilizado aporte teórico da Análise Crítica do Discurso

1 Mestre pelo Programa de Pós-graduação da Universidade Estadual do Oeste do Paraná - UNIOESTE, área de concentração Linguagem e Sociedade.

2 Doutorado em Ciência Política, pela Universidade Federal do Rio Grande do Sul (UFRGS), docente do Programa de PósGraduação em Letras, da Universidade Estadual do Oeste do Paraná - UNIOESTE 
(doravante ACD), por Fairclough (1997, 2001) e Van Dijk (2008). A escolha teórica em ACD, em meio à pesquisa educacional foi devido à compreensão e entendimento de que a mudança social é constante em nossa sociedade, e que este ensino trazido pela PA, constitui além do ensino básico, trabalho com a parte social, histórica e ideológica dos alunos.

Segundo Gimonet,

aprender é um processo de mudança, uma construção e não uma colocação, uma acumulação, uma soma ou uma superposição de noções. Aprender é estar construindo conhecimentos, capacidades novas, e, mais globalmente, se construir a si próprio. Aprender significa encontrar uma resposta às necessidades, às vontades, aos desejos, à curiosidade, à identidade... do momento. Aprender é ligar, conectar com o existente, superando "saberes adquiridos" já presentes. (GIMONET, 2007, p.134)

Outro ponto fundamental, é que a ACD, atenua possibilidades de uma análise nos modelos diferenciados de educação, pelo entendimento de que a língua não é neutra, para a ACD sempre há um ponto de vista uma posição tomada pelo sujeito, ele não é assujeitado, é dono de suas escolhas. Fairclough (2001) entende que o discurso é produzido a partir de valores ideológicos, criados e recriados com base na realidade do sujeito.

Neste sentido entendemos que a grande diferença entre o ensino tradicional e a proposta da $\mathrm{PA}$, está no que compreende a ACD como o lugar social do sujeito, que determina as prioridades de ensino. Ou seja, no ensino tradicional a tendência é repassar aos alunos aquilo que lhes foi previamente determinado, ou por livros didáticos, por apostilas, ou outros materiais disponibilizados, que nada, ou pouco condizem com a realidade do aluno. Já a PA, entende como importantes a realidade do aluno, une a teoria da sala de aula com a prática do aluno na família e comunidade, onde o discurso escolar torna-se realidade, atendendo ao anseios dos alunos e familiares, no que concerne a utilização do que se aprende com aquilo que necessita aprender.

VanDijk (2008) acrescenta que em grupos sociais com maior acesso, aqueles que tem oportunidade de aprendizado, inclusive aos discursos públicos, conseguem difundir aos demais grupos a sua ideologia, estabelecendo além da relação de poder com demais grupos, uma valorização de sua própria comunidade.

Nas escolas há uma diversidade de culturas, podendo ser diferenciadas nas famílias, comunidades, igrejas, entre outros grupos que se estabelecem ideologicamente. Diferenças estas e que, de certa forma, padroniza o conhecimento da juventude. A partir desta reflexão é que podemos entender que a escola tradicional, nas mais diversas vezes, não trabalha com e para a realidade do aluno, o que acaba repetindo a imposição de única ideologia. Para Braga

os discursos que circulam na instituição escolar tanto podem contribuir para manter quanto para transformar as relações de dominação entre os sujeitos. Os educadores, nesse processo, são os responsáveis pela reprodução de muitos dos discursos que inferiorizam certos grupos sociais. Isso pode ocorrer pelos discursos oriundos do estado que, por meio de propostas, diretrizes, currículo, material didático, encaminhamentos em cursos de formação continuada ou outros, veiculam ideologias que favorecem alguns grupos sociais e marginalizam outros. Os educandos são aqueles que recebem esses discursos e nem sempre possuem leitura de mundo suficiente para compreenderem que existem outras possibilidades de interpretação, além daquelas direcionadas pelo livro didático. (BRAGA, 2013, p.17)

Em paralelo ao ensino tradicional a PA, apesar de atender a mesma quantidade de ideologias, é voltada a realidade dos alunos, com perspectivas de aprendizado reais o que acaba viabilizando que o aluno aprenda a partir de sua realidade. Mesmo a PA atendendo aos conteúdos 
básicos estabelecidos pela Base Nacional Comum Curricular, o conhecimento é adaptado com o que o aluno traz de casa, cada um aprimora o aprendizado a sua realidade, fazendo com que esse discurso monopolizado e apoderado socialmente seja minimamente influenciador em suas atividades corriqueiras e sociais. Dessa forma a PA apresenta uma perspectiva diferenciada de ensino de acordo com a realidade do aluno.

Para melhor compreensão, o artigo, será dividido em três partes. A primeira contextualizará o surgimento da PA e apresentará a proposta da teoria de Freire (1981-1987) e Gimonet (2007) como um método de ensino diferenciado. $\mathrm{O}$ segundo apresentará de forma breve resgate do pressuposto teórico de ACD, e por fim considerações finais que trazem elementos presentes na ACD e na PA, que embora sejam linhas teóricas diferentes, ambas trabalham com o social e seu contexto.

\section{Pedagogia da alternância}

Em primeira instância é preciso compreender o termo pedagogia, como toda técnica utilizada para a educação, como sendo métodos de encaminhamento educacional, práticas ou estratégias de aprendizado. Para Franco; Libâneo; Pimenta (2011) a Pedagogia está vinculada à ação formativa ou educativa em todas as circunstâncias da vida. Como a pedagogia liga a educação à sociedade. A pedagogia recebeu várias terminologias devido às

instituições de formação de educadores incidirem posições que identificaram os estudos sobre o fenômeno educativo, ora como Pedagogia geral (Ciência Pedagógica), ora como Ciência da Educação ou Ciências da Educação e até a identificação da Pedagogia com o ensino. (FRANCO; LIBÂNEO; PIMENTA, p. 59, 2011)
Como todo processo de reconhecimento a algo novo, a pedagogia passou por longo processo de constituição, caracterização, conhecimento até que pudesse ser conhecida e aperfeiçoada como ramo da educação. No Brasil foi confundida com didática, e só definida posterior como:

o termo Pedagogia designa um determinado campo de conhecimentos com especificidade epistemológica, cuja natureza constitutiva é a teoria e a prática da Educação ou a teoria e a prática da formação humana, e a Didática, o ramo da Pedagogia que trata do processo de ensino e aprendizagem. (FRANCO; LIBÂNEO; PIMENTA, p. 61, 2011)

Neste sentido podemos aprimorar o conceito de pedagogia aos métodos educacionais capazes de agir na formação educacional e humana. Sendo assim todo e qualquer processo de aprendizagem pode ser compreendido como uma parte da pedagogia, que não necessariamente tenha que estar vinculada a uma escola, mas sim às teorias e práticas, pois educação não é constitutivo exclusivo das salas de aula, mas de toda sociedade.

Ao conceituar pedagogia, precisamos entender que ao longo do tempo houve estruturas de formação nas instituições de ensino, sendo caracterizadas como três grandes tendências, ou três grandes correntes, importantes para identificar as concepções de aprendizagem de cada época:

Corrente da pedagogia tradicional centralizada
no programa e no docente; Corrente da
pedagogia ativa centralizada na pessoa
em formação; e Corrente da pedagogia
centralizada na realidade que pode também
ser chamada de corrente da pedagogia da
complexidade e na qual se situe a Pedagogia
da Alternância. (GIMONET, 2007, p.108)

A corrente da pedagogia tradicional, é a mais utilizada nas escolas, que obriga o professor a cumprir programa específico e pré determinado. O professor é detentor do saber, o aluno o receptor 
de conhecimento. Segue os modelos do sistema educacional imposto pelo estado. Que segundo Gimonet (2007) uma organização escolar do tipo racional, burocrático e diretivo.

A corrente a da pedagogia ativa, também conhecida como escola nova, o aluno tem autonomia de aprendizado, o docente se torna mediador do conhecimento, identifica apresenta, mas não interfere. $\mathrm{O}$ aluno aprende se forma e se educa, o docente se adapta ao aluno. De acordo com Gimonet (2007) esta orientação pedagógica acentua a autonomia da criança e sua especificidade em relação ao adulto.

E a corrente centrada na realidade, engloba a Pedagogia da Alternância, pois entende que conhecimento e aprendizado estão em todos os lugares, não só na sala de aula, cada pessoa desde que nasce constrói sua formação educacional ao longo do tempo. Paulo Freire (1987) defendia que a escola tinha como objetivo ensinar o aluno a ler o mundo para então transformá-lo.

A escola deve ser adaptada a realidade do aluno, unindo a teoria à prática diária, tendo em vista que a vida fora da sala de aula é mais ampla que dentro da escola. Gimonet (2007) considera todos os componentes da vida da pessoa e da instituição escolar como cadinho de formação e de educação.” É nesta corrente que a alternância se instaura, na tentativa de unir a teoria com a prática, cuja qual teve seu início há muito tempo atrás.

A alternância não é de ontem. A aprendizagem das profissões aconteceu durante muito tempo por imitação e transmissão direta no terreno da prática. Sem dúvida, alguns processos de alternância entre a teoria e a prática existiram em tempos mais recuados, mas é na Idade Média que um deles aparece, na França, como compagnonnage - ou seja, um tipo de associação que visa a instrução profissional e a ajuda mútua, uma corporação. (GIMONET, p. 112, 2007)
A alternância foi utilizada em muitas experiências, por trabalhar com a teoria e a prática, contribuindo com o conhecimento da profissão, da realidade das crianças e jovens. Nos séculos XVI e XVII destacam-se atividades para minimizar o problema de crianças abandonadas à miséria, num intuito de incluí-las no ambiente natural e social, com perspectiva na própria realidade. Nos séculos XVII e XVIII criou-se entre outras a escola dominical, que atendiam as crianças somente no domingo, pois durante a semana elas precisavam trabalhar. Em XVIII um grupo de engenheiros foi a campo aprender junto com seus professores sobre a arquitetura, numa perspectiva de alternância. Depois vem a era da industrialização, onde nos termos de alternância, que une a prática e o conhecimento, as escolas atendiam a demandas das indústrias capacitando para o mercado de trabalho produtivo. Por muito tempo a alternância era considerada como a aprendizagem de profissões. (GIMONET, p.112115, 2007).

A PA iniciou sua trajetória de discussões e surgimento a partir de uma estrutura escolar adaptada ao Brasil como Escola Família Rural e posterior Casa Familiar Rural, teve seu início no sudoeste da França, especificamente na comunidade de Sérignac-Peboudou, em Lotet-Garone, no ano de 1935, era chamada de Maisons Familiares Rurales (MFRs), demandado de um descontentamento dos camponeses daquela região, em relação ao sistema educacional que seus filhos participavam e que não condizia com as atividades desenvolvidas no meio rural (ESTEVAN, 2003).

Segundo Estevan (2003) a França passava na década de 30 , por crises econômicas e sociais, devido à derrota sofrida na Primeira Guerra Mundial para a Alemanha, que afetou diretamente a agricultura, necessitando de um longo processo de reconstituição. Porém o estado, apesar de 
a maioria da população ser de agricultores, enfatizou a educação escolar nos centros urbanos, direcionada às questões urbanistas e desenvolvimento da mão-de-obra em indústrias e comércio, ocasionando a evasão escolar de muitos jovens que não se encontravam neste contexto escolar, que pretendiam e necessitavam, por questões econômicas, priorizar a vida no campo e seu desenvolvimento.

Sendo conhecedor de que o ser humano, é movido pelas necessidades, sejam elas de sobrevivência ou de conforto, e que a partir dessas é que se geram as transformações e modificações sociais, humanas e econômicas, é que entendemos que os camponeses da França, se viram obrigados a encontrar uma forma de unir o conhecimento escolar às suas atividades econômicas, evitando a evasão dos jovens da escola e reconstruindo a vida no campo. Nesta perspectiva é que os agricultores, que tinham seus filhos vinculados a essa educação proposta pelo Estado, não condizente com a realidade do campo, buscaram soluções, num intuito de manter os jovens na escola, mas sem abandonar a vida camponesa.

De acordo com Estevan (2003) após longas discussões entre os agricultores e comunidades vizinhas, com o mesmo propósito, e numa tentativa de solucionar o problema existente, com apoio do Sindicato Rural, que tinha força social mais relevante na época, auxiliados ainda, por alguns membros do SCIR (Secretaria Central de Iniciativa Rural), uma organização sindical com objetivo de incentivar e apoiar iniciativas voltadas ao desenvolvimento rural, é que as discussões ganharam força para propor uma educação diferenciada. O primeiro agricultor que chamou a atenção a questão da necessidade de uma nova metodologia para a educação foi Jean Peyrat, membro do SCIR, devido à atitude de seu filho, em abandonar a escola na tentativa de reconstruir e sobreviver com a família no campo. Peyrat relatou a situação ao Sindicato Rural, o qual assumiu a causa se envolvendo e promovendo discussões com os demais agricultores, que se viam na mesma situação, procurando uma alternativa para manter os filhos na escola, e ao mesmo tempo no campo, mas que principalmente unissem o conhecimento à prática. Apesar de ter sido um processo lento e de muita discussão, aliados também com propostas advindas da religião, e do JAC (Juventude Agrícola Cristã), as ações foram se expandindo, até a criação de um projeto por meio das articulações de desenvolvimento da SCIR.

Assim em 1935, surgiu a primeira turma de MFR, com apenas cinco jovens, entre 13 e 14 anos, sendo considerado como um projeto de vivência, num funcionamento que demandava uma semana na escola (com aulas teóricas) e três em casa (utilizando o conhecimento teórico na prática da agricultura). Essa estrutura inicialmente criada para atender as necessidades dos camponeses da França, mais tarde deu origem e campo de estudo a muitos pesquisadores, e que hoje é conhecido como "Pedagogia da Alternância (PA)". O projeto inicial funcionava em regime de internato nas instalações da igreja da comunidade, onde os alunos aprendiam os conhecimentos técnicos e científicos, e depois desenvolviam a prática dentro das propriedades, unindo as técnicas à necessidade da atividade no campo, o que propiciava o estudo e trabalho no meio rural, sem um comprometer o outro, mas um contribuindo com o outro. Ao "unir o útil ao agradável", a junção de teoria e prática, se percebeu os jovens mais motivados e interessados, tanto no aprendizado quanto no trabalho, além da percepção de maior envolvimento com a comunidade a que estavam inseridos. (ESTEVAN, 2003)

Com a proposta francesa, de um modelo diferenciado de educação, que busca emergir a realidade ao conhecimento técnico e teórico, a partir de discussões, e formações discursivas, 
acrescidas de lutas e disputas, a PA ficou conhecida e respeitada no Brasil, na perspectiva educacional, principalmente nas CFR e posterior se expandiu a outros ensinos, como no ensino superior.

Após um longo período das primeiras experiências das CFR implementadas no Brasil, expandiu-se o campo discursivo no âmbito educacional como um método de ensino diferenciado. Ganhou espaço e legalidade, embasado em 1996, pela Lei de Diretrizes e Bases - Lei 9394/96, cuja qual, prevê no Art. 23:

A educação básica poderá organizar-se em séries anuais, períodos semestrais, ciclos, alternância regular de períodos de estudos, grupos não-seriados, com base na idade, na competência e em outros critérios, ou por forma diversa de organização, sempre que o interesse do processo de aprendizagem assim o recomendar. (LDB, 1996)

A partir da possibilidade de interpretação pedagógica, regulamentada pela "alternância regular de períodos de estudos" e pela "forma diversa de organização", é que foi possível desenvolver pelo modelo francês da PA, sendo caracterizada por um ensino diferenciado, voltado a realidade do estudante, levando em consideração o exterior da sala de aula, a vivência fora da escola.

Com base também no Art. 28 da LDB:

$\mathrm{Na}$ oferta de educação básica para a população rural, os sistemas de ensino promoverão as adaptações necessárias à sua adequação às peculiaridades da vida rural e de cada região, especialmente: I - conteúdos curriculares e metodologias apropriadas às reais necessidades e interesses dos alunos da zona rural; II - organização escolar própria, incluindo adequação do calendário escolar às fases do ciclo agrícola e às condições climáticas; III - adequação à natureza do trabalho na zona rural. (LDB, 1996)

Cujo qual prevê diferentes organizações no sistema de ensino, focando sempre o processo de aprendizagem. Garantindo à população rural adaptações às especificidades do campo e da região visando à educação básica de qualidade.

Esse método voltado para as diferentes realidades, grupos e comunidades possibilita ao aluno uma maior interação entre o conhecimento e a prática. Neste universo de especificidades, encontram-se histórias de vidas diferentes, cada qual com sua realidade, mas que se engajam numa mesma tentativa de aprender. Conhecimento adquirido tanto na escola, quanto nos períodos em casa, e na comunidade. A PA atende as demandas diferenciadas da sociedade, embasadas pela LDB, proporciona aos estudantes um contato maior com a prática diária, advindas da realidade.

Afinal aprender e ensinar devem seguir na mesma direção, pois "existir é assim, um modo de vida que é próprio ao ser capaz de transformar, de produzir, de decidir, de criar, de recriar, de comunicar-se". (FREIRE, 1981, p.53).

Para Gimonet (2007) a "alternância surge como um recurso", com quatro finalidades: a primeira como meio de orientação profissional; a segunda como adaptação ao emprego, sendo que a escola deve permitir ao estudante que ingressar no profissional a implementação e utilização rápida da formação teórica e prática; a terceira enquanto qualificação profissional, unindo a escola e a empresa ou propriedade sem confrontar um com o outro; e a quarta finalidade a da formação geral, que não se trata de passar por cima do ensino tradicional, mas de oferecer outras vias de formação pessoal, profissional e educativa.

Compreender a PA para Gimonet (2007) significa:

perceber, além dos procedimentos acionados e dos jogos institucionais, que é o "alternante" e ele só - que está no centro da complexidade, que constrói, aprende, se forma, se 
educa, cresce do seu jeito obedecendo os processos permanentes de auto-organização, de autoconstrução, de autonomização progressiva. É perceber, em seguida, que os monitores têm como missão de propor os instrumentos e as atitudes apropriadas para facilitar a orquestração de todos os componentes de formação e de educação ao alcance de cada alternante. (GIMONET, p. $153,2007)$

Ou seja, a PA busca além de auxiliar na construção do conhecimento, demandar utilidade para tal aprendizado do estudante, que este utilize os ensinamentos diretamente em suas atividades diárias, para que o ensino não fique vagando perdido dentro dos conteúdos, mas que tenham uma prática diária, no processo de construção do ensino e aprendizagem por meio da teoria e da prática.

Com a alternância tenta-se juntar, alcançar, unificar, embora sempre muito parcialmente, tudo isto. [...] Uma outra escola em tempo integral, no dia-a-dia da vida, em vários lugares, para estudar, aprender, continuamente, de maneira inter e transdisciplinar. Uma outra escola que não opõe mais a teoria e a prática, porque existe prática, teoria, conceito em todo lugar. Porque a mão e o pensamento se juntam sempre. Porque o saber é a ação e a ação é o saber. Um outro paradigma escolar a adquirir a tornar vivo, mas que supõe desfazer-se do anterior que nos modelou. Evolução, e até às vezes revolução, a operar nas nossas cabeças. (GIMONET, p. 128-129, 2007)

Um novo campo educacional abriu portas a um ensino diferenciado, que valorize o aluno enquanto sujeito na sociedade, capaz de conhecimento teórico, e de prioridades práticas. Ou seja, um aluno que aprende na teoria, e que coloca em prática no seu dia a dia, valorizando o que faz, e ao mesmo tempo aperfeiçoando seu trabalho.

O ser humano é inacabado, está em constante transformação, assim como o conhecimento não é essa coisa feita e acabada e a consciência é "intencionalidade" ao mundo.
Ao nível humano, o conhecimento envolve a constante unidade entre ação e reflexão sobre a realidade. (FREIRE, 1981, p.53).

\section{A Análise Crítica do Discurso}

A Análise Crítica do Discurso (doravante, ACD) no Brasil ainda engatinha na questão de obras teóricas, entre as que podemos citar como principais fontes de pesquisa, destaca-se Magalhães (1986; 2000), que dá base a muitas pesquisas de cunho acadêmico, entre outros artigos, teses e dissertações lançados no últimos, resultado de pesquisas embasadas principalmente em Fairclough e Vandijk ou por obras originais em inglês ou por tradutores brasileiros, como é o caso de: Resende \& Ramalho (2006), Resende (2009) e Ramalho e Resende (2011).

A ACD surgiu na década de 1980, na Universidade de Lancaster, a partir da publicação,em 1985, de um artigo intitulado Critical Discourse Analysis, no Journal of Pragmatics, de autoria de Norman Fairclough, no qual o autor apresentou pela primeira vez o termo e a perspectiva de um discurso crítico. Porém, somente em 1991, a ACD teve seu reconhecimento público, em Amsterdã, na Holanda, durante um simpósio sobre teoria e métodos para análise do discurso, em cuja oportunidade reuniram-se estudiosos e pesquisadores, entre eles Norman Fairclough, Teun Van Dijk, GuntherKress, Theo Van Leeuwen e Ruth Wodak. Este evento foi considerado a marca inicial da ACD, pois permitiu a apresentação de um novo modelo de análise do discurso. As obras publicadas a partir desse simpósio tiveram grande importância para o desenvolvimento da ACD. Das obras, destacam-se a revista Discourse and Society e os livros: Language and Power, de Fairclough (1989), Language, power and ideology, de Wodak (1989), Prejudice in discourse de Van Dijk (1984). 
Apesar da fase inicial da ACD ser considerada a partir de 1980, VanDijk (2008) sinalizou que já havia tendências e fundamentos da linguística crítica e da ACD em construção, as quais já contradiziam os paradigmas formais dominantes nas décadas de 1960 e 1970 :

Alguns dos fundamentos da ACD já podem ser encontrados na teoria crítica da Escola de Frankfurt antes da Segunda Guerra Mundial. [...] Enfoques similares à ACD também podem ser encontradas em certas tendências "críticas" da sociolingüística, da psicologia e das ciências sociais (VANDIJK, 2008, p. 113).

A ACD, por ter um papel fundamental com a sociedade e também por atuar contra paradigmas formais dominantes, possui aspectos que podem ser discutidos em diferentes áreas, pois, segundo VanDijk, "objetiva oferecer um 'modo' ou uma 'perspectiva' diferente de teorização, análise e aplicação ao longo de todos os campos" (VANDIJK, 2008, p. 114). Com tais afirmações, o autor destaca que traços similares aos apresentados posteriormente como análise crítica, podem ser encontrados muito antes da teorização em ACD.

A ACD é compreendida, como uma disciplina sem regras de análise pronta, sem uma única teoria aos estudos, devido à vasta abrangência de áreas, e ao foco principal ser a sociedade. Fairclough e Wodack, segundo VanDijk (2008), apresentam alguns principais fundamentos da ACD, que podem ser encontrados na maioria das pesquisas, sendo:

1) A ACD aborda problemas sociais; 2) As relações de poder são discursivas; 3) $\mathrm{O}$ discurso constitui a sociedade e a cultura; 4) O Discurso realiza um trabalho ideológico; 5) O discurso é histórico; 6) A relação entre texto e sociedade é mediada; 7) A análise do discurso é interpretativa e explanatória;

8) O discurso é uma forma de ação social (VANDIJK, 2008, p. 115).
$\mathrm{Na}$ ACD, Fairclough, se concebe a interface linguagem-ideologia muito estreitamente (FAIRCLOUGH, 2001), ou seja, discute-se as mudanças sociais na sociedade moderna, e as influências de lutas e poder sobre a linguagem nas relações sociais. Além disso, Trabalha com a prática social e suas transformações no mundo, buscando justamente o que se modifica, o que se transforma na sociedade. Nesse sentido, o autor afirma:

O que se busca é uma análise de discurso que focalize a variabilidade, a mudança e a luta: variabilidade entre as práticas e heterogeneidade entre elas como reflexo sincrônico de processos de mudança histórica que são moldados pela luta entre as forças sociais (FAIRCLOUGH, 2001, p.58).

Fairclough propôs a teoria social do discurso, como um método para estudar a mudança social, examinando "não apenas o papel da linguagem na reprodução das práticas sociais e das ideologias, mas também seu papel fundamental na transformação social" (FAIRCLOUGH, 2001, p.11). O autor explica, ainda, como a abordagem crítica é compreendida no âmbito da ACD:

\footnotetext{
As abordagens críticas diferem das abordagens não-crítica, não apenas na descrição das práticas discursivas, mas também ao mostrarem como o discurso é moldado por relações de poder e ideologias e os efeitos construtivos que o discurso exerce sobre as identidades sociais, as relações sociais e os sistemas de conhecimento e crença (FAIRCLOUGH, 2001, p.32).
}

$\mathrm{Na}$ visão de Fairclough, a $\mathrm{ACD}$ não busca só o que molda o discurso, as formações discursivas e ideológicas, mas todo o processo social envolvido, as mudanças que ocorrem nas relações sociais e que provocam tais formações. 
A constituição discursiva da sociedade não emana de um livre jogo de ideias nas cabeças das pessoas, mas de uma prática social que está firmemente enraizada em estruturas sociais materiais, concretas, orientando-se para elas. (FAIRCLOUGH, 2001, p.93)

As pessoas vivem em um meio social já estabelecido, com regras e atribuições prontas, para cada etapa da vida uma forma de comportamento é idealizado e orientado, ou seja, quando criança tem suas obrigações em obedecer aos pais, aos mais velhos e fazer pequenas atividades, ao ser jovem deve pensar no futuro em sua formação, trabalhar para construir sua própria "vida" . Na fase adulta o ser humano é responsável pelos filhos, pela comunidade, etc. Cada etapa da vida é condicionada a práticas sociais estabelecidas por uma estrutura moldada pela própria sociedade e que há muito tempo segue o percurso da vida orientando as novas gerações. Práticas sociais que não estão escritas nem documentadas, mas que pelo senso comum já faz parte da vida naturalmente. Neste sentido VanDijk (2008) enfatiza que o:

Poder social é uma característica da relação entre grupos, classes ou outras formações sociais, ou entre pessoas na qualidade de membros sociais. Apesar de podermos falar em formas pessoais de poder, esse poder individual é menos relevante para a explicação sistemática do poder no discurso enquanto interação social. (VANDIJK, 2008, p.41)

O ensino, na sua imposição ao social, começa pelas opções: pública e privada, depois ao condicionamento de uma ideologia padronizada, com direitos e acesso à educação de qualidade para todos. Qualidade e acesso, condicionados a alguns, com interesses próprios, que submetem ao demais uma "democracia" forçada. Uma crença, por hora real, de que os detentores de discursos bem elaborados e informações precisas são detentores do poder público, poder esse que tem voz ativa na sociedade. VanDijk (2008) caracteriza neste sentido, não somente o uso do poder, mas principalmente o abuso de poder, que é chamado por ele de "dominação".

Abuso de poder é o uso ilegítimo do poder. [...] significa a violação de normas e valores fundamentais no interesse daqueles que têm o poder e contra os interesses dos outros. Os abusos de poder significam a violação dos direitos sociais e civis das pessoas. $\mathrm{Na}$ área do discurso e da comunicação, isso pode significar o direito de ser bem ensinado e educado, de ser bem informado, etc. (VANDIJK, 2008, p.29)

Para tanto, a ACD se constitui justamente na parte em que o poder é abusivo, ou seja, além dessa disputa incansável do ser humano, o poder toma rumos excessivos. Para VanDijk:

A ACD é um tipo de investigação analítica discursiva que estuda principalmente o modo como o abuso de poder, a dominação e a desigualdade são representados, reproduzidos e combatidos por textos orais e escritos no contexto social e político. [...] os analistas críticos do discurso adotam um posicionamento explícito e, assim, objetivam compreender, desvelar e, em última instância, opor-se à desigualdade social (VANDIJK, 2008, p.113).

O abuso de poder ocorre quando a sociedade é pouco ou quase nada informada, aceitando o que the é imposto de forma tranquila, sem se opor, sem questionar. Para isso também a ACD trabalha no sentido de que,

[...] mais análises críticas são necessárias para descobrir se essa diversidade de tecnologias, mídias, mensagens e opiniões faz com que o cidadão seja melhor informado e capaz de resistir à manipulação através de mensagens que aparentam ser direcionadas pessoalmente para ele - mas que poderiam implementar muito bem as ideologias dominantes que não mudaram muito (VANDIJK, 2008, p.20).

O poder a que se relata a ACD é o poder social, aquele que é exercido por uma posição social, seja na educação, política, saúde, entre 
outras instâncias que detém poder de forma "naturalizada" e, segundo VanDjik (2008), caracterizada como poder simbólico, ou seja, o cargo que exerce na sociedade dá poder sobre ela, por exemplo: o professor tem poder sobre os alunos, enquanto professor e detentor de conhecimento. Neste caso, podemos encontrar o abuso de poder na imposição de conteúdo previamente estabelecido pelos cronogramas de aula, livros didáticos impostos pelo Ministério da Educação, que embora o professor tenha o poder sobre sua aula, é limitado a outro poder, que o submete ao ensino a ser reproduzido pelas classes dominantes, camuflado nas atividades diárias de sala de aula, pré- aprovadas e estabelecidas por um grupo de outros professores que entendem que esta é a melhor forma de ensinar. Não se atem, portanto, à grande diversidade da sociedade, numa tentativa de padronizar o conhecimento, fazendo com que todos pensem da forma estabelecida pelo poder, neste caso, daqueles que estão à frente da educação, detentores de poderes sociais.

Muitas outras áreas são molduradas com poderes sociais, e pelo abuso dele também, o que faz com que cresça cada vez mais a instigante necessidade por estudos em ACD que se posicionem frente a uma sociedade acostumada ao comodismo, a aceitar que tudo esteja pronto porque deve ser assim. O analista crítico, além de estudar as transformações e problemas sociais, deve se posicionar frente a estes problemas, a fim de proporcionar respaldo para debates contrários aos existentes. Nesse sentido, cada vez mais é importante ter clareza das ideologias impostas pelos grupos de dominação, para que possam ser encaradas de forma clara e objetiva as transformações ocorridas na sociedade, compreendendo-as de maneira crítica e não impositiva.

O analista que se propõe a uma investigação crítica do discurso, diferente de outras áreas que são consideradas neutras, necessita se posicionar em relação a sua pesquisa. Para isso, VanDijk elenca alguns pontos, chamados por ele de requisitos:

Como ocorre com outras tradições de pesquisa mais marginais, a investigação em ACD deve ser "melhor" que qualquer outra investigação aceita.

- A ACD concentra-se principalmente nos problemas sociais e nas questões políticas, no lugar de paradigmas correntes e modismos.

- A análise crítica de problemas sociais, empiricamente adequada, é normalmente multidisciplinar.

- Em vez de meramente descrever estruturas do discurso, a ACD procura explicá-las em termos das propriedades da interação social e especialmente da estrutura social.

- $\quad$ ACD enfoca, mais especificamente, os modos como as estruturas do discurso produzem, confirmam, legitimam, reproduzem ou desafiam as relações de poder e de dominação na sociedade (VANDJIK, 2008, p.115-116).

Para fazer uma análise crítica, o analista deve ter seu ponto de vista formado em relação às transformações ocorridas na sociedade e nos problemas nele encontrados. Embora seja conhecedor das ideologias opostas, é necessário que encare sua visão de forma a defender um lado ou outro; afinal, para uma analise crítica, não há neutralidade. Um analista crítico deve ter em mente alguns fundamentos:

1) A ACD aborda problemas sociais; 2) As relações de poder são discursivas; 3) $\mathrm{O}$ discurso constitui a sociedade e a cultura; 4) $\mathrm{O}$ discurso realiza um trabalho ideológico; 5) O discurso é histórico; 6) A relação entre texto e sociedade é mediada; 7) A análise do discurso é interpretativa e explanatória; 8) O discurso 
é uma forma de ação social (VANDJIK e WODAK, 2008, p.115-116).

A ACD, embora não tenha uma teoria pronta, por se tratar das mudanças sociais, se fundamenta nas propostas dos seus fundadores, que entendem não ser uma análise pronta, mas que devem seguir alguns pontos para que se compreenda como ACD, principalmente em relação às abordagens discursivas, problemas sociais e abusos de poder.

VanDijk inicialmente chamava a atual ACD de Estudos Críticos do Discurso (ECD), enfatizando que esses estudos "devem ser capazes de contribuir para a mudança social" (VANDJIK, 2008, p.17).

Compreendendo que estudos sobre a sociedade, seu discurso e transformações são principais ferramentas de análise crítica social, podemo concluir que a PA proporciona um aprendizado social, pois leva em consideração toda a realidade do aluno, trabalhando não só com o aprendizado do aluno, mas também com o que o aluno vai levar para a sociedade.

\section{Considerações finais}

Tanto a PA, quanto a ACD buscam atender e entender o contexto social, fazendo com que a prática social seja de fato levada em consideração, seja pela educação, seja para análises de discursos. Unir a teoria e a prática requer conhecimento além do que esta demandado. Para a PA, interessa conhecer a realidade do aluno, para que o ensino de fato tenha sua função social. Para a ACD precisa conhecer o contexto social para compreender e analisar discursos.

Comparar a ACD de Fairclough (1997, 2001) e Van Dijk (2008), a outros teóricos de linhas diferentes como Freire (1981-1987) e Gimonet (2003), torna a compreensão da pesquisa nas áreas sociais, muito mais relevante.
Apesar de serem teorias distantes, e áreas de estudos diferentes, ambas valorizam e necessitam da sociedade e seu contexto, cada uma em sua ênfase teórica.

É importante enfatizar que a mudança na sociedade é constante, e com isso há a necessidade de compreensão tanto dos fatores que ocasionam tais mudanças estudadas pela ACD, como formas de manter o ensino nessa sociedade de acordo com a realidade vivenciada, cuja qual é tarefa da PA. Pois segundo Freire (1981, p.17) "vale dizer, como seres que, transformando o mundo com seu trabalho, criam o seu mundo." Ou seja, os seres humanos são capazes de transformar sua própria sociedade, e recriá-la da sua maneira. E nesta perspectiva é que as pesquisas buscam, além de entender as mudanças ocorridas (ACD), orientar nessa nova dimensão estabelecida (PA).

Tanto a ACD, quanto a PA entendem que a língua não é neutra, e que o discurso é produzido a partir de valores ideológicos, criados e recriados com base na realidade do sujeito (Fairclough, 2001).

A PA leva em consideração a realidade do aluno, fazendo com que o discurso se torne real, o aluno é visto como um sujeito incluso a uma sociedade e que necessita ao mesmo tempo adaptar-se e contribuir com ela, no sentido de que seu ensino torna-se prática diária, e sua prática serve como ensino. Assim também a ACD compreende que cada sujeito tem seu lugar social e deve ser analisado em seu contexto, não de forma isolada, pois mesmo no discurso há a reciprocidade de teoria e prática, ou no caso da ACD de discurso e contexto, e vice-versa.

A PA contribui para que os alunos sejam capazes de aplicar o conhecimento à prática, aprender e compreender não só teoria, mas também a prática aplicando-a na sua vida e na sociedade. A ACD auxilia para que o aprendizado e a compreensão possam ser questionados, 
aprimorado e compreendido. Duas linhas de pesquisa diferentes, mas que se unem, a partir da necessidade de questionar o mundo e os acontecimentos, e que o contexto interfere diretamente no sujeito e também no seu discurso enquanto sujeito social.

Enfim podemos comparar a ACD e a PA, como duas linhas teóricas diferentes, mas com foco de pesquisa parecida, embora cada uma estabeleça relações de análises diferentes, ambas trabalham com o social, com o sujeito na sociedade, seja pelo discurso, seja pelas mudanças sociais. Entender a ACD e a PA nos proporciona compreender como as mudanças ocorrem na sociedade, além disso, identificar e apreender a lidar com o novo, com novos acontecimentos discursivos e educacionais.

\section{Referências}

BRAGA, M. A. N. Os discursos veiculados sobre a mulher e o negro no livro didático público do estado do Paraná - língua portuguesa e literatura: ensino médio. Dissertação. Salvador 2013

ESTEVAM, D. O. Casa Familiar Rural: A formação com base na pedagogia da alternância em Santa Catarina - MFRs: Da origem a atualidade, Florianópolis, 2001.

FAIRCLOUGH, N. Discurso e mudança social. Tradução: Izabel Magalhães, Editora Universidade de Brasília, Brasília, 2001.

Discurso, mudança e hegemonia.

In.PEDRO, E.R. (org.). Análise crítica do Discurso: uma perspectiva sociopolítica e funcional. Caminho. Lisboa, 1997. discurso e formações discursivas: uma proposta de abordagem da práxis dicursiva, Revista Icarahy Edição n.04 out.2010.

FRANCO, M.A.S; LIBÂNEO, J. C; PIMENTA, S.G. As dimensões constitutivas da Pedagogia como campo de conhecimento. Ano 14 - n. 17 - julho 2011 - p. 55-78, Blo Horizonte, 2011.

FREIRE, Paulo. Ação cultural para a liberdade. $5^{a}$ ed., Rio de Janeiro, Paz e Terra, 1981.

\section{Pedagogia} do

Oprimido. $17^{\text {a }}$ Ed. Rio de Janeiro: Paz e Terra, 1987.

GIMONET, J. Praticar e compreender a pedagogia da alternância dos CEFFAs, Editora Vozes, Petrópolis - Rio de Janeiro, 2007.

\section{LDB - Lei de Diretrizes e Bases da Educação}

Nacional, Lei no 9.394, de 20 de dezembro de 1996. <http://portal.mec.gov.br/arquivos/ pdf/ldb.pdf $>$ acesso em 05.dez.2015

RESENDE, Viviane de M; RAMALHO, Viviane. Análise do Discurso Critica. 2. Ed., $2^{a}$ reimpressão. Contexto. São Paulo, 2014.

VANDIJK, Teun A. Discurso e poder, Contexto, São Paulo, 2008.

Artigo enviado em: 27/12/2016 Aceite em: 27/06/2017

FONSECA, R. O. Condições de produção do 